\title{
Prognostic value of postoperative proteinuria in cardiac surgery: a pilot study
}

\author{
[Valeur pronostique de la protéinurie postopératoire en chirurgie cardiaque: \\ une étude pilote]
}

Keyvan Karkouti MD, ${ }^{\star \dagger}$ Shahriar Shayan MD, ${ }^{\star}$ Duminda N. Wijeysundera MD, ${ }^{*}$ Stuart A. McCluskey MD, ${ }^{*}$ Mohammed Ghannam BSc, ${ }^{*}$ W. Scott Beattie MD ${ }^{*}$

Background: Proteinuria is a non-specific marker of inflammation that may reflect the glomerular component of systemic capillary leak. The objective of this pilot study was to determine if postoperative proteinuria is associated with adverse outcomes following cardiac surgery with cardiopulmonary bypass.

Methods: Eligible patients were individuals undergoing cardiac surgery with cardiopulmonary bypass who did not have severe pre-existing renal dysfunction. Urine was collected after induction of anesthesia (baseline) and two to four hours after arrival to the intensive care unit (ICU). Proteinuria was measured as random protein creatinine ratio in $\mathrm{g} \cdot \mathrm{mol}^{-1}$. Adverse events were defined $a$ priori as prolonged ICU stay ( $\geq 90$ th percentile) and organ dysfunction. The relationship between proteinuria and adverse events was assessed by bivariate (Chi-square or Fisher's exact tests) and multivariable (multiple logistic regression) analyses.

Results: The study included 197 (of 243 eligible) patients. Postoperative proteinuria (protein creatinine ratio $\geq 30 \mathrm{~g} \cdot \mathrm{mol}^{-1}$ ) was associated with prolonged ( $\geq$ four days) ICU stay [odds ratio (OR) 7.0; 95\% confidence interval $(\mathrm{Cl}) 2.8-17.1]$ and organ dysfunction (OR 3.9; $\mathrm{Cl}$ I.9-8.I). After adjustment for confounders, proteinuria was associated with a 3.2 -fold increase in the odds of both prolonged ICU stay (CI I.I-9.7) and organ dysfunction ( $\mathrm{Cl}$ I.4-7.0).

Conclusions: Proteinuria two to four hours after cardiac surgery with cardiopulmonary bypass may be a useful marker for systemic capillary leak and adverse postoperative events. Large prospective studies are needed to confirm these findings.
Objectif: La protéinurie est un marqueur non spécifique de l'inflammation qui peut illustrer la composante glomérulaire d'une fuite capillaire systémique. Nous voulions déterminer si la protéinurie postopératoire est associée à des complications de la chirurgie cardiaque avec circulation extracorporelle.

Méthode : Les patients admissibles devaient subir une opération cardiaque avec circulation extracorporelle, mais ne devaient pas présenter de dysfonction rénale sévère préexistante. L'urine a été recueillie après l'induction de l'anesthésie (conditions de départ) et entre deux et quatre heures après l'arrivée à l'unité des soins intensifs (USI). La protéinurie a été mesurée comme le ratio aléatoire protéine-créatinine en $\mathrm{g} \cdot \mathrm{mol}^{-1}$. Les événements indésirables ont été définis a priori : un séjour prolongé à l'USI ( $\geq 90^{\circ}$ percentile) et une dysfonction organique. La relation entre la protéinurie et les événements indésirables a été évaluée par des analyses bivariée (chi carré et tests exacts de Fisher) et multivariée (régression logistique multiple).

Résultats : L'étude a porté sur 197 des 243 patients admissibles. La protéinurie postopératoire (ratio protéine créatinine $\geq 30$ $\mathrm{g} \cdot \mathrm{mol}^{-1}$ ) a été associée à un séjour prolongé ( $\geq$ quatre jours) à I'USI [risque relatif (RR) 7,0; intervalle de confiance de $95 \%$ (IC) $2,8-I 7, I]$ et à une dysfonction organique (RR 3,9; IC I,9-8,I). Après ajustements pour les facteurs de confusion, la protéinurie $a$ été associée à 3,2 fois d'augmentation des risques relatifs du séjour prolongé à I'USI (IC I,I-9,7) et de la dysfonction organique (IC I,4-7,0).

Conclusion : La protéinurie mesurée deux à quatre heures après une intervention en chirurgie cardiaque avec circulation extracorporelle peut être un marqueur indiquant une fuite capillaire systémique et des événements postopératoires indésirables. Ces résultats devront être confirmés dans de grandes études prospectives.

From the Departments of Anesthesia* and Health Policy, Management, and Evaluation, ${ }^{\dagger}$ University Health Network, University of Toronto, Toronto, Ontario, Canada.

Address correspondence to: Dr. Keyvan Karkouti, University Health Network, Toronto General Hospital, Department of Anesthesia, EN 3-402, 200 Elizabeth Street, Toronto, Ontario M5G 2C4, Canada. Phone: 416-340-5164; Fax: 416-340-3698;

E-mail: keyvan.karkouti@uhn.on.ca

Sources of support: K. Karkouti is supported in part by the Canadian Institutes of Health Research and the Canadian Blood Services. D.N. Wijeysundera is supported by the Canadian Institutes of Health Research. W.S. Beattie is the R. Frasier Elliot Chair of Cardiac Anesthesia at the University Health Network. No third party funding was used for this study. None of the authors have any affiliation with or financial involvement in any organization or entity with a direct financial interest in the subject manner or materials discussed in the manuscript. Accepted for publication November 14, 2005.

Revision accepted December 19, 2005. 


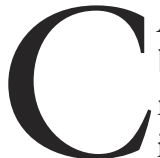

ARDIAC surgery with cardiopulmonary bypass (CPB) provokes a systemic inflammatory reaction. ${ }^{1}$ Possible causes of this inflammatory reaction include operative trauma, blood loss or transfusion, contact of the blood components with the artificial surface of the bypass circuit, ischemia-reperfusion injury, and endotoxemia. ${ }^{1,2}$ The severity of the inflammatory reaction after cardiac surgery and its consequent complications vary widely among patients. In most patients, the reaction is mild and without clinical sequelae. In about $10 \%$ of patients, however, the reaction is marked and is associated with severe systemic derangements that can culminate in multi-organ dysfunction syndrome and death.

The potentially serious consequences of the systemic inflammatory response after cardiac surgery underscore the need for an early and sensitive marker of disease severity. Fundamental to the pathogenesis of severe inflammatory reaction culminating in multiorgan dysfunction syndrome is a systemic capillary leak. ${ }^{3,4}$ Proteinuria, a non-specific marker of inflammation that is thought to reflect the glomerular component of systemic capillary leak, ${ }^{3}$ may therefore be a useful marker of organ dysfunction and death after cardiac surgery. Proteinuria has previously been shown to be strongly associated with adverse outcomes in sepsis, trauma, and vascular surgery. ${ }^{5-11}$ Aside from a small study of low-risk patients, the ability of proteinuria to predict adverse outcomes after cardiac surgery remains unknown. ${ }^{12}$ The objective of this prospective cohort pilot study was to examine the association between postoperative proteinuria and adverse outcomes in patients undergoing cardiac surgery with $\mathrm{CPB}$.

\section{Patients and methods}

\section{Study setting}

The Toronto General Hospital is a teaching hospital affiliated with the University of Toronto. A full range of adult cardiac surgery procedures were performed by 13 surgeons during the study period. Approval for this study was obtained from the University Health Network Research Ethics Board, and informed consent was obtained from all patients before surgery.

\section{Study population}

Consecutive patients undergoing any non-emergent cardiac surgery with CPB during the months of July and August of 2003 and 2004 were approached for inclusion in the study. The only exclusion criterion was pre-existing marked renal dysfunction (creatinine clearance of $<25 \mathrm{~mL} \cdot \mathrm{min}^{-1}$ or dialysis dependence). Creatinine clearance was estimated using the Cockcroft-Gault equation.

\section{Clinical practice}

During the study period, patients were managed according to standardized clinical guidelines. ${ }^{13}$ Patients were pre-medicated with lorazopam 1 to 2 mg sl. Anesthesia with fentanyl $\left(10-20 \mu g \cdot \mathrm{kg}^{-1} i v\right)$, midazolam $\left(0.1 \mathrm{mg} \cdot \mathrm{kg}^{-1} i \mathrm{v}\right)$, pancuronium $(0.15-$ $\left.0.20 \mathrm{mg} \cdot \mathrm{kg}^{-1} i \mathrm{v}\right)$, isoflurane $(0.5-1.5 \%$ end-tidal), and propofol $\left(0.5-4 \mathrm{mg} \cdot \mathrm{kg}^{-1} \cdot \mathrm{hr}^{-1} i v\right)$ was employed. Pulmonary artery and urinary catheters were inserted after induction of anesthesia.

Antifibrinolytics [50 to $100 \mathrm{mg} \cdot \mathrm{kg}^{-1}$ of tranexamic acid (Cyclokapron, Pharmacia \& UpJohn Inc, Mississauga, ON, Canada) or $6 \times 10^{6} \mathrm{U}$ of aprotinin (Trasylol, Bayer AG, Leverkusen, Germany) $6 \times 10^{6}$ $\mathrm{U}]$ were routinely administered. Anticoagulation was achieved with heparin to maintain an activated clotting time above $480 \mathrm{sec}$. The CPB circuit was primed with 1.8 L of Ringer's lactate and $50 \mathrm{~mL}$ of $20 \%$ mannitol. Albumin (25\%) and synthetic colloids (Pentaspan) were added to the circuit as needed. Management of CPB included systemic temperature drift to $34^{\circ} \mathrm{C}$, alpha-stat $\mathrm{pH}$ management, targeted mean perfusion pressure between $50-70 \mathrm{mmHg}$, and pump flow rates of 2.0-2.4 L. $\mathrm{min}^{-1} \cdot \mathrm{m}^{2}$. Myocardial protection was achieved with intermittent antegrade and, occasionally, retrograde blood cardioplegia. When necessary, deep hypothermic circulatory arrest was achieved by cooling to $20^{\circ} \mathrm{C}$ with or without retrograde cerebral perfusion.

During $\mathrm{CPB}$, red blood cell concentrate (RBC) was transfused to maintain the hematocrit concentration above 17-19\%. Pericardial blood was salvaged into the cardiotomy suction reservoir and re-infused via the $\mathrm{CPB}$ circuit for as long as patients were anticoagulated. After separation from CPB, heparin was neutralized over ten to $15 \mathrm{~min}$ with protamine sulphate ( $1 \mathrm{mg}$ per $100 \mathrm{U}$ of heparin) to achieve an activated clotting time within $10 \%$ of baseline. Post-CPB, $\mathrm{RBC}$ was transfused to maintain the hematocrit at or above $24 \%$. All units of RBC were leukoreduced by the Canadian Blood Services during the study period. Other blood products were transfused according to standard clinical guidelines. ${ }^{14}$

\section{Urine collection and analysis}

The gold standard for quantitative urine protein assessment is the $24 \mathrm{hr}$ urine protein excretion. ${ }^{15}$ This measure, however, is difficult to obtain postoperatively owing to the need for timed (overnight or 24 hr) urine collection. A surrogate measure for $24 \mathrm{hr}$ urine protein excretion is random urine protein concentration, measured as a ratio with urine creatinine concentration to correct for variation in hydration. ${ }^{15}$ 
Random urine protein creatinine ratio (PCR), which has been shown to provide accurate estimates of the urinary protein excretion rate in a variety of settings, ${ }^{15}$ was used in this study.

Urine samples $(10 \mathrm{~mL}$ each) were obtained from patients after insertion of the urinary catheter postinduction of anesthesia (baseline sample) and two to four hours after arrival to the intensive care unit (ICU), (postoperative sample). Urine samples were collected from the burette chamber of the urinary catheter drainage bag, rested on ice, and sent to the hospital laboratory for analysis. Urinalysis was carried out by the Bayer ADVIA $1650^{\mathrm{TM}}$ (Bayer HealthCare, Tarrytown, NY, USA); urinary protein was measured using immunoturbidimetry method and creatinine was measured using Jaffe's method.

\section{Measured variables and outcomes}

Detailed patient demographics, co-morbidities, and intraoperative data were prospectively collected on all patients.

Postoperative adverse outcomes were defined as prolonged ICU stay and organ dysfunction. The cutoff for prolonged ICU stay was the 90th percentile in the sample population, which was four days. This cut-off was selected because it would identify the $10 \%$ of the population most likely to have had perioperative complications while providing an adequate number of patients for multivariable analysis to control for the effects of confounders. Organ dysfunction was defined as any of the following: cardiac - low output syndrome [use of inotropes (other than low-dose dopamine) for $>$ six hours to maintain a cardiac index $\geq 2 \mathrm{~L} \cdot \mathrm{min}^{-}$ ${ }^{1} \cdot \mathrm{m}^{2}$ ], myocardial infarction (troponin I > $10 \mu \mathrm{g} \cdot \mathrm{L}^{-1}$ and new electrocardiogram changes consistent with infarction), and new-onset atrial fibrillation; respiratory - prolonged intubation (duration $\geq 90$ th percentile of the study population) or re-intubation; cerebral - new stroke or delirium; renal - requirement for dialysis or $>50 \%$ increase in serum creatinine; hepatic $->20 \%$ deterioration in liver function as measured by serum enzymes. All outcomes were adjudicated by a research assistant from patients' medical records.

\section{Statistical analyses}

Statistical analyses were performed using SAS $^{\mathrm{TM}}$ version 8.2 (SAS Institute, Inc., Cary, NC, USA). Categorical variables were summarized as frequencies and percentages, continuous variables as means and standard deviations if normally distributed, and medians and inter-quartile range if not normally distributed.

The Mann-Whitney $U$ test was used to assess differences in baseline and postoperative PCR (con- tinuous variable) in patients with and without adverse outcomes. Since the normal distribution of PCR after cardiac surgery is not known, a cut-off for dichotomizing PCR into normal and elevated was identified as follows. The Chi-square or Fisher's exact tests were used to assess the relationship between postoperative PCR and the two measured outcomes (prolonged ICU stay and organ dysfunction) at various cut-offs, and PCR was dichotomized at the cut-off where the relationship was strongest (as measured by sensitivity and specificity).

The unadjusted association between elevated postoperative PCR (dichotomized at the identified cutoff) and measured outcomes was assessed by the Chi-square or Fisher's exact tests. The sensitivity, specificity, and predictive value of elevated PCR were calculated.

Bivariate analysis (Chi-square or Fisher's exact test for categorical variables and Mann-Whitney $U$ test for continuous variables) was carried out to identify preoperative and intraoperative factors associated with elevated postoperative PCR (dichotomized). Variables associated $(P<0.1)$ with postoperative PCR (i.e., potential confounders) were included in the multivariable logistic regression analysis as covariates in order to obtain the independent relationship between elevated postoperative PCR and adverse outcomes (using backward variable selection and $P<0.05$ for variable retention). Multivariable analysis was also carried out in the subgroup of patients that excluded those with elevated baseline PCR and in the subgroup that excluded those with postoperative renal dysfunction.

\section{Results}

During the study period, 243 patients were eligible for the study. Of these, 220 consented to the study, but surgery was delayed or cancelled in 16 patients and postoperative PCR was not obtained in seven patients. Thus, 197 patients were available for analysis. Major complications in the cohort included: one death, two strokes, and five myocardial infarctions. While there were no cases of renal failure requiring dialysis, nine patients developed acute renal dysfunction (> 50\% increase in serum creatinine).

In the entire cohort, the median baseline PCR was $11 \mathrm{~g} \cdot \mathrm{mol}^{-1}$ (inter-quartile range $7-18 \mathrm{~g} \cdot \mathrm{mol}^{-1}$ ) and the median postoperative PCR was $18 \mathrm{~g} \cdot \mathrm{mol}^{-1}$ (inter-quartile range $\left.1 \mathrm{l}-30 \mathrm{~g} \cdot \mathrm{mol}^{-1}\right) ; P<0.0001$. The distribution of baseline and postoperative PCR values in patients based on the occurrence of measured outcomes are illustrated in the Figure.

Based on the unadjusted relationship between postoperative PCR and measured outcomes, $30 \mathrm{~g} \cdot \mathrm{mol}^{-1}$ 


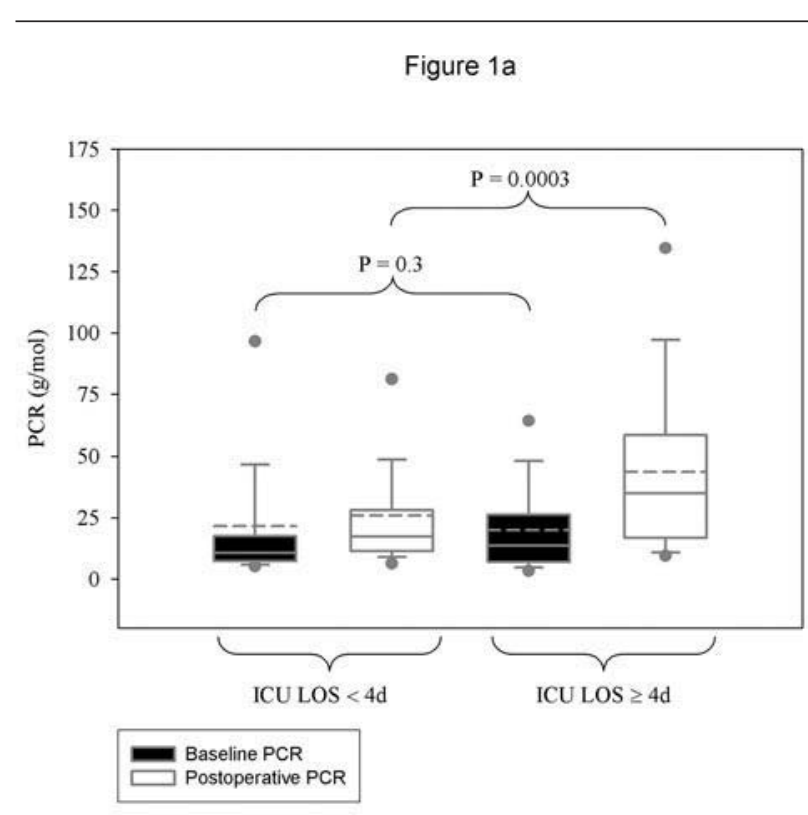

Figure $1 \mathrm{~b}$

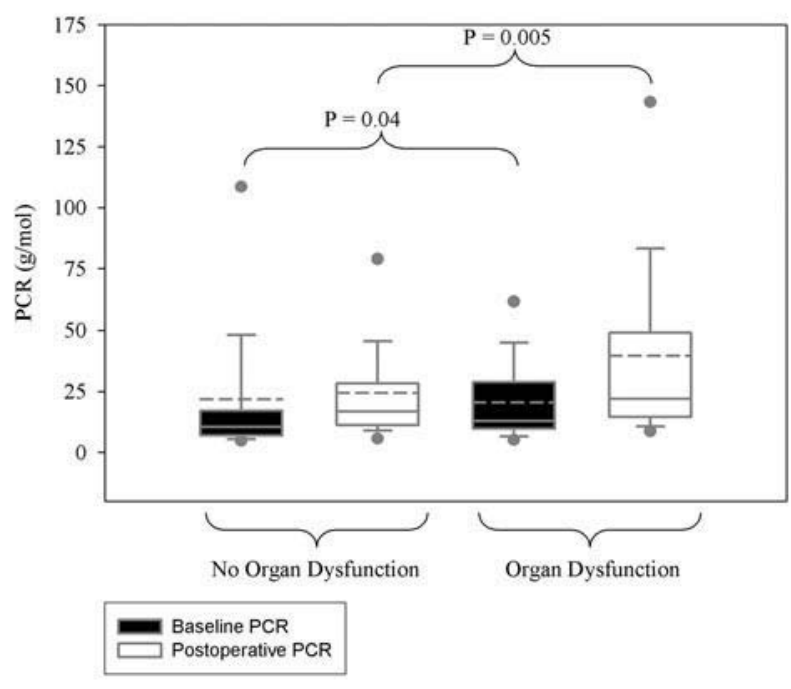

FIGURE Box plots of protein creatinine ratio values for outcomes. a) intensive care unit stay. b) Organ dysfunction. The boundary of the box closest to zero indicates the 25 th percentile, a line within the box marks the median, and the boundary of the box farthest from zero indicates the 75 th percentile. Whiskers (error bars) above and below the box indicate the 90th and tenth percentiles. Circles indicate the 95 th and fifth percentiles. Dashed line indicates the mean. Differences compared by the Mann-Whitney U test.

was selected as the cut-off for dichotomizing PCR into normal and abnormal. The unadjusted relationships between dichotomized postoperative PCR and
TABLE I Unadjusted relationship of postoperative proteinuria with adverse outcomes in the entire patient population

\begin{tabular}{llll}
\hline Ontcomes & $\begin{array}{l}P C R \geq 30 \mathrm{~g} \cdot \mathrm{mol}^{-1} \\
(n=51)\end{array}$ & $\begin{array}{l}P C R<30 \mathrm{~g} \cdot \mathrm{mol}^{-1} \\
(n=146)\end{array}$ & P value \\
\hline ICU stay $\geq 4$ days & $16(31.4 \%)$ & $9(6.2 \%)$ & $<0.0001$ \\
Organ dysfunction $21(41.2 \%)$ & $22(15.1 \%)$ & 0.0001 \\
\hline PCR = protein creatinine ratio; ICU $=$ intensive care unit.
\end{tabular}

TABLE II Unadjusted relationship of postoperative proteinuria with adverse outcomes in subgroup of patients with baseline $\mathrm{PCR}<30 \mathrm{~g} \cdot \mathrm{mol}^{-1}$

\begin{tabular}{llll}
\hline Outcomes & $\begin{array}{l}P C R \geq 30 \mathrm{~g} \cdot \mathrm{mot}^{-1} \\
(n=39)\end{array}$ & $\begin{array}{l}P C R<30 \mathrm{~g} \cdot \mathrm{mot}^{-1} \\
(n=126)\end{array}$ & P value \\
\hline ICU stay $\geq 4$ days & $11(28.2 \%)$ & $8(6.4 \%)$ & 0.0002 \\
Organ dysfunction & $15(38.5 \%)$ & $16(12.7 \%)$ & 0.0003 \\
\hline PCR = protein creatinine ratio; ICU = intensive care unit.
\end{tabular}

outcomes are shown in Table I for the entire sample and in Table II for the subgroup with baseline PCR < $30 \mathrm{~g} \cdot \mathrm{mol}^{-1}$. In the entire sample, the unadjusted odds ratios of prolonged ICU stay and organ dysfunction associated with elevated PCR were 7.0 [confidence interval (CI) 2.8-17.1] and 3.9 (CI 1.9-8.1), respectively. For prolonged ICU stay in the entire sample, elevated PCR had a sensitivity, specificity, positive predictive value, and negative predictive value of $64 \%$, $80 \%, 31 \%$, and $94 \%$, respectively. For organ dysfunction in the entire sample, the values were $49 \%, 81 \%$, $41 \%$, and $85 \%$, respectively.

The bivariate relationships between PCR and preoperative and intraoperative variables are shown in Table III. The following variables that were related to elevated postoperative PCR were included in the multivariable analyses as potential confounders: age, gender, stroke, atrial fibrillation, renal dysfunction, diuretic use, digoxin use, excessive blood loss (> 5 $\mathrm{U}$ RBC transfusion), CPB duration, and circulatory arrest. The results of the multivariable analyses for the two outcomes studied are shown in Tables IV and V. As can be seen, elevated postoperative PCR was independently associated with a 3.2-fold increase in the odds of prolonged ICU stay (CI 1.1-9.7) and a 3.2 -fold increase in the odds of organ dysfunction (CI 1.4-7.0). This association was consistent in the subgroup analyses that excluded patients with elevated baseline PCR or postoperative renal dysfunction (results not shown).

\section{Discussion}

Major systemic insults such as cardiac surgery can provoke a severe systemic inflammatory reaction that 
TABLE III Bivariate relationships of preoperative and intraoperative variables with postoperative PCR

\begin{tabular}{|c|c|c|c|}
\hline & $\begin{array}{l}P C R \geq 30 \mathrm{~g} \cdot \mathrm{mol}^{-1} \\
(n=51)\end{array}$ & $\begin{array}{l}P C R<30 \mathrm{~g} \cdot \mathrm{mol}^{-1} \\
(n=146)\end{array}$ & P value \\
\hline \multicolumn{4}{|l|}{ Patient characteristics } \\
\hline Age $(y r)$ & $63 \pm 14$ & $57 \pm 14$ & $<0.05$ \\
\hline Weight (kg) & $81 \pm 24$ & $83 \pm 17$ & 0.2 \\
\hline Female gender & $23(45.1 \%)$ & $38(26.0 \%)$ & $<0.05$ \\
\hline Hypertension & $26(51.0 \%)$ & $74(50.7 \%)$ & 0.9 \\
\hline Peripheral vascular disease & $5(9.8 \%)$ & $11(7.5 \%)$ & 0.6 \\
\hline Stroke & $6(11.8 \%)$ & $4(2.7 \%)$ & $<0.05$ \\
\hline Smoker & $6(11.8 \%)$ & $19(13.0 \%)$ & 0.9 \\
\hline Congestive heart failure (within 2 weeks of surgery) & $7(13.7 \%)$ & $14(9.6 \%)$ & 0.4 \\
\hline Left ventricular dysfunction & $9(17.7 \%)$ & $18(12.3 \%)$ & 0.4 \\
\hline Pulmonary hypertension & $9(17.7 \%)$ & $11(7.5 \%)$ & 0.06 \\
\hline Atrial fibrillation & $15(29.4 \%)$ & $17(11.6 \%)$ & $<0.05$ \\
\hline ß-adrenergic blocking drug use & $23(45.1 \%)$ & $71(48.6 \%)$ & 0.7 \\
\hline Calcium channel blocking drug use & $14(27.4 \%)$ & $26(17.8 \%)$ & 0.2 \\
\hline Angiotensin-converting-enzyme inhibitor use & $26(51.0 \%)$ & $71(48.6 \%)$ & 0.8 \\
\hline Diuretic use & $22(43.1 \%)$ & $33(22.6 \%)$ & $<0.05$ \\
\hline Digoxin use & $12(23.5 \%)$ & $11(7.5 \%)$ & $<0.05$ \\
\hline Hemoglobin $\left(g \cdot \mathrm{L}^{-1}\right)$ & $111 \pm 23$ & $113 \pm 26$ & 0.8 \\
\hline Platelet count $\left(\times 10^{9}\right)$ & $184 \pm 91$ & $171 \pm 77$ & 0.4 \\
\hline \multicolumn{4}{|l|}{ Surgical variables } \\
\hline Complex surgery & $36(70.6 \%)$ & $63(43.2 \%)$ & $<0.05$ \\
\hline Non-elective surgery & $15(29.4 \%)$ & $33(22.6 \%)$ & 0.3 \\
\hline Previous sternotomies & $3(5.9 \%)$ & $3(2.0 \%)$ & 0.2 \\
\hline Units of RBC transfused & $2(0,4)$ & $0(0,3)$ & $<0.05$ \\
\hline $\mathrm{CPB}$ duration $(\mathrm{min})$ & $123 \pm 39$ & $93 \pm 30$ & $<0.05$ \\
\hline Circulatory arrest & $4(7.8 \%)$ & $1(0.7 \%)$ & $<0.05$ \\
\hline
\end{tabular}

$\mathrm{PCR}=$ protein creatinine ratio; $\mathrm{RBC}=$ red blood cell; $\mathrm{CPB}=$ cardiopulmonary bypass. Continuous variables are presented as means \pm standard deviations if normally distributed or medians (inter-quartile range) if not normally distributed, and as $n$ (percentage) if categorical.

TABLE IV Logistic regression results for prolonged ICU stay as the outcome

\begin{tabular}{lll}
\hline & OR and CI for outcome & P value \\
\hline PCR $\geq 30 \mathrm{~g} \cdot \mathrm{mol}^{-1}$ & $3.2(1.1-9.7)$ & 0.03 \\
$>5 \mathrm{U}$ of $\mathrm{RBC}$ transfused & $8.9(2.2-29.4)$ & 0.001 \\
$\mathrm{CPB}$ duration $>150$ min & $4.1(1.01-16.7)$ & 0.049 \\
Preoperative renal dysfunction & $8.1(2.2-30.2)$ & 0.002
\end{tabular}

Model's Hosmer-Lemeshow test $P=0.6$; C-index $=0.81$

ICU $=$ intensive care unit; $\mathrm{OR}=$ odds ratio; $\mathrm{CI}=$ confidence interval PCR $=$ protein creatinine ratio; $\mathrm{RBC}=$ red blood cells; $\mathrm{CPB}=$ cardiopulmonary bypass; Renal dysfunction $=$ creatinine $>$ $100 \mu \mathrm{mol} \cdot \mathrm{L}^{-1}$ in women and $>110 \mu \mathrm{mol} \cdot \mathrm{L}^{-1}$ in men.

is characterized by increased systemic vascular permeability, a condition that has been referred to as the "capillary leak syndrome". ${ }^{4}$ Proteinuria is thought to reflect the glomerular component of this systemic capillary leak. Under normal conditions, nearly all of the proteins that are filtered through the glomeruli
TABLE V Logistic regression results for organ dysfunction as the outcome

\begin{tabular}{lll}
\hline & OR and CI for outcome & P value \\
\hline PCR $\geq 30 \mathrm{~g} \cdot \mathrm{mol}^{-1}$ & $3.2(1.4-7.0)$ & 0.004 \\
$>5$ U of RBC transfused & $2.5(1.7-3.9)$ & $<0.0001$ \\
Previous stroke & $5.5(2.4-13.0)$ & 0.03
\end{tabular}

Model's Hosmer-Lemeshow test $P=0.7$; C-index $=0.763$

$\mathrm{OR}=$ odds ratio $; \mathrm{CI}=$ confidence interval $; \mathrm{PCR}=$ protein creatinine ratio; $\mathrm{RBC}=$ red blood cells.

are reabsorbed by mechanisms that operate close to saturation. ${ }^{16}$ Owing to the direct relationship between glomerular permeability and systemic vascular permeability; ${ }^{16}$ one would expect that when vascular permeability is increased as part of the capillary leak syndrome, glomerular protein filtration would also be 
increased and proteinuria would ensue in direct proportion to the severity of the capillary leak syndrome. Studies finding a strong association between degree of proteinuria and severity of systemic inflammation $6,10,17$ and adverse outcomes ${ }^{5-12}$ support this hypothesis. If proteinuria, as measured by random urine RCR, is an accurate early marker for severity of the capillary leak syndrome, it may therefore function as a simple, noninvasive, inexpensive, and validated ${ }^{18}$ screening test for this condition and its harmful sequelae.

In this prospective cohort study in cardiac surgery with $\mathrm{CPB}$, we found that proteinuria (defined as PCR $\geq 30 \mathrm{~g} \cdot \mathrm{mol}^{-1}$ ) during the early postoperative period was independently associated with prolonged ICU stay and organ dysfunction. When no adjustments for confounders were made, patients with elevated postoperative PCR had a seven-fold greater odds of prolonged ICU stay and about a four-fold greater odds of organ dysfunction than those with normal postoperative PCR. After controlling for confounders, elevated PCR was associated with about a three-fold increase in the odds of prolonged ICU stay and organ dysfunction. For comparison, the two other independent predictors of prolonged ICU stay that remained in our multivariable analysis - massive blood loss and prolonged $\mathrm{CPB}$ duration - were associated with an eight-fold and a four-fold increase in the odds of prolonged ICU stay, respectively.

The association of postoperative proteinuria and adverse events after cardiac surgery has been examined in only one other study. ${ }^{12}$ In that study, which included 40 low-risk patients who underwent coronary artery bypass grafting with $\mathrm{CPB}$, proteinuria (measured as random urine albumin creatinine ratio) two hours after CPB was found to be associated with respiratory and renal dysfunction. ${ }^{12}$ Others have also examined the association between proteinuria (or albuminuria) after major acute systemic insults and adverse events in other patient populations. ${ }^{5-12}$ In all but two of these studies, ${ }^{9,10}$ such an association was found. These studies, however, were limited by small sample sizes, assessment of surrogate outcomes, and in all except one ${ }^{8}$ failure to account for the effects of confounders such as renal dysfunction and diabetes.

The current pilot study, which included a homogeneous cardiac surgery patient population and controlled for the effects of confounders, therefore, adds important information on the relationship between proteinuria after major systemic insults and adverse events. It is important to note, however, that the results of this pilot study are by no means definitive given that this study was also limited by its use of a surrogate measure for urine protein extraction, small sample size, and use of surrogate outcomes. Proteinuria in this study was measured by random PCR, and the cut-off of $30 \mathrm{~g} \cdot \mathrm{mol}^{-1}$ was identified based on the relationship between PCR and the measured outcomes. Random PCR has been validated as a surrogate measure for urine protein extraction as measured by timed urine collection, with $25 \mathrm{~g} \cdot \mathrm{mol}^{-1}$ considered as the threshold for clinical proteinuria. ${ }^{15}$ The correlation of PCR with urine protein extraction after cardiac surgery, however, has not been tested. Moreover, neither the normal distribution of PCR nor its relationship to the systemic inflammatory syndrome in cardiac surgery is known. Thus, PCR as it was used in this study may not provide an accurate estimate for urine protein extraction or severity of the systemic inflammatory response.

Another limitation of the study was its small sample size, which precluded us from fully exploring the role of all potential confounding variables on the results or to assess the independent relationship between elevated PCR and clinically important outcomes such as mortality. Rather, we were limited to assessing the relationship of PCR with prolonged length of ICU stay (with the cut-off selected as the 90th percentile in the sample population) and a composite organ dysfunction outcome.

Thus, even though this and other studies suggest that postoperative proteinuria, when measured as random urine protein (or albumin) creatinine ratio, is a promising marker for severity of inflammatory response, larger, more definitive clinical studies are necessary to determine its independent discriminative ability for adverse clinical events in cardiac surgery, and to determine whether or not it is predictive enough for clinical or research use. Potential clinical applications of this test would include provision of more accurate prognosis to patients and families and better resource allocation. Potential research applications would include its use as a surrogate outcome for assessing the efficacy of investigational therapies aimed at attenuating postoperative systemic inflammatory response (as has been done in a study of $i$ volume expanders). ${ }^{12}$

In summary, this study found that at two to four hours after cardiac surgery with $\mathrm{CPB}$, proteinuria, as estimated by random PCR, was associated with prolonged ICU stay and organ dysfunction. Future studies, however, are needed to definitively determine whether or not PCR is independently associated with clinically relevant adverse events in order to delineate its role in clinical practice and research studies. 


\section{References}

1 Paparella D, Yau TM, Young E. Cardiopulmonary bypass induced inflammation: pathophysiology and treatment. An update. Eur J Cardiothorac Surg 2002; 21: 232-44.

2 Laffey JG, Boylan JF, Cheng DC. The systemic inflammatory response to cardiac surgery. Anesthesiology 2002; 97: 215-52.

3 Evans G, Greaves I. Microalbuminemia as predictor of outcome. Shows promise but large prospective trials are needed. BMJ 1999; 318: 207-8.

4 Zikria BA, Bascom JU. Mechanisms of multiple system organ failure. In: Zikria $\mathrm{BA}, \mathrm{Oz} \mathrm{MO}$, Carlson $\mathrm{RW}$ (Eds). Reperfusion Injuries and Clinical Capillary Leak Syndrome. Armonk: Futura Publishing Company; 1994: 443, 489.

5 Szakmany T, Molnar Z. Increased glomerular permeability and pulmonary dysfunction following major surgery: correlation of microalbuminuria and $\mathrm{PaO}_{2} / \mathrm{FiO}_{2}$ ratio. Acta Anaesthesiol Scand 2004; 48: 704-10.

6 Koike K, Aiboshi J, Shinozawa $\Upsilon$, Sekine K, Endo T, Yamamoto $\Upsilon$. Correlation of glomerular permeability, endothelial injury, and postoperative multiple organ dysfunction. Surg Today 2004; 34: 811-6.

7 Gosling P, Brudney S, McCrath L, Riseboro S, Manji M. Mortality prediction at admission to intensive care: a comparison of microalbuminuria with acute physiology scores after 24 hours. Crit Care Med 2003; 31 : 98-103.

8 Thorevska N, Sababi R, Upadya A, Manthous C, Amoateng-Adjepong $\Upsilon$. Microalbuminuria in critically ill medical patients: prevalence, predictors, and prognostic significance. Crit Care Med 2003; 31: 1075-81.

9 Bianchi RA, Silva NA, Natal ML, Romero MC. Utility of base deficit, lactic acid, microalbuminuria, and C-reactive protein in the early detection of complications in the immediate postoperative evolution. Clin Biochem 2004; 37: 404-7.

10 De Gaudio AR, Spina R, Di Flippo A, Feri $M$.

Glomerular permeability and trauma: a correlation between microalbuminuria and injury severity score. Crit Care Med 1999; 27: 2105-8.

11 Pallister I, Gosling P, Kaya A, Bradley S. Prediction of posttraumatic adult respiratory distress syndrome by albumin excretion rate eight hours after admission. J Trauma 1997; 42: 1056-61.

12 Brudney CS, Gosling P, Manji M. Pulmonary and renal function following cardiopulmonary bypass is associated with systemic capillary leak. J Cardiothorac Vasc Anesth 2005; 19: 188-92.

13 Karkouti K, Wijeysundera DN, Yau TM, et al. Platelet transfusions are not associated with increased morbidity or mortality in cardiac surgery. Can J Anesth 2006; 53:
279-87.

14 American Society of Anesthesiologists. Practice guidelines for blood component therapy. A report by the American Society of Anesthesiologists Task Force on Blood Component Therapy. Anesthesiology 1996; 84: 732-47.

15 National Kidney Foundation. K/DOQI clinical practice guidelines for chronic kidney disease: evaluation, classification and stratification. Am J Kidney Dis 2002; 39(Suppl 1): S1-266.

16 Jensen JS, Borch-Johnsen K, Jensen G, Feldt-Rasmussen $B$. Microalbuminuria reflects a generalized transvascular albumin leakiness in clinically healthy subjects. Clin Sci 1995; 88: 629-33.

17 Sarti A, De Gaudio R, Messineo A, Cuttini M, Ventura $A$. Glomerular permeability after surgical trauma in children: relationship between microalbuminuria and surgical stress score. Crit Care Med 2001; 29: 1626-9.

18 Jensen JS, Clausen P, Borch-Johnsen K, Jensen G, FeldtRasmussen B. Detecting microalbuminuria by urinary albumin/creatinine concentration ratio. Nephrol Dial Transplant 1997; 12(Suppl 2): 6-9. 